Research Article

\title{
A Non Convex Cost Function Based Optimal Load Dispatch using TLBO Algorithm
}

\author{
DSNMRAO* and Niranjan Kumar
}

Department of Electrical \& Electronics Engineering, National Institute of Technology Jamshedpur, Jharkhand, India-831014

Received 23 February 2016; Accepted 29 March 2017

\begin{abstract}
This paper presents recent methods for Economic Load Dispatch Problems. This work concentrates on a new optimization algorithm that is Teaching and Learning $(T \& L)$ based optimization. Incorporated $T \& L$ based optimization algorithm is an effective remedy for diminishing the flaws in the traditional approach like provincial optimal trapping, inadequate effective to identify nearby extreme points and inefficient mechanism for analyzing the constraints. According to our T \& L based optimization algorithm a learner can gain knowledge in two ways: (i) by teacher (called teacher phase) and (ii) interacting with the neighbor learners (called learner phase). In this algorithm learners are called as population. Design variable are called as subjects of the learners. The best learner is treated as Teacher. This paper proposes the effectiveness of T\&L based Optimization on 6 unit test system, 10 unit test system and compared with Particle Swarm Optimization (PSO), Differential Evolution (DE), Harmony Search Algorithm (HSA) with considering transmission losses and finally T \& L based optimization technique gives the high quality solution.
\end{abstract}

Keywords: Economic dispatch, valve point loadings effects, T \& L based optimization, PSO, DE, HSA

\section{Introduction}

As a Power Engineer scheduling the generators is very big Problem. Since from the past so many techniques are in practice for the economic load dispatch. Economic load dispatch means optimal allocation of loads to the generators so as to maintain power supply must be equal to load demand also to decrease the losses and fuel cost [1]. We are all know that power generation is highly costlier. In countries like India the major power generation is form thermal power plants only where the running cost is very high. The one of the best way to reduce the cost and losses of power plants is to Economic dispatch of loads [2-4]. Researchers developed lot of methods for Economic load dispatch. In this work concentrates on a new optimization algorithm that is teaching and learning based optimization. Electrical power plays vital role for any county development. For achieving proper load demand we should have the optimal power flow generation to reduce the cost of production and this can be achieved by economic load dispatch with proper integration of sources to the load centers. The main motto of Economic Load Dispatch (ELD) is to build effective power flow path while compromising all constraints. The cost function of each alternator can be represented with quadratic function and it can solve by several optimization techniques such as Lambda iteration and gradient based methods in convention ELD problem [57].

Anciently we developed many methods to clear up the ELD problem like mathematical programming methods and these are more delicate to stating points and periodically

E-mail address: 2015rsee003@nitjsr.ac.in

ISSN: $1791-2377 @ 2017$ Eastern Macedonia and Thrace Institute of Technology. All rights reserved. converge to local optimum solution or diverge altogether. Linear programming approaches are quick and effective but the main bad thing is correlated with the piecewise linear cost. Nonlinear programming approaches have a problem of convergence and algorithmic complexity. Newton based approaches cannot handle many number of equality constraints [8-9].

This paper explains TLBO algorithm to solve ELD problem with valve point loading effect of thermal plants by considering transmission losses. We proposed the effectiveness of T\&L based Optimization on 6 unit test system and compared with PSO, DE, HSA. Finally T \& L based optimization technique gives the high quality solution.

\section{Economic Load Dispatch Formulation}

Economic load dispatch means minimizing the fuel cost, balanced Real power, and satisfying real power demand. The Problem formulation for Economic load dispatch is shown below [10].

$$
F C\left(P_{i}\right)=\sum_{i=1}^{N} F_{i}\left(P_{i}\right)
$$

Where $F C\left(P_{i}\right)=$ Total fuel cost, $N=$ Total number of thermal generating unit, $P_{i}=$ Power generation of $i^{\text {th }}$ thermal generating unit

The fuel cost is quadratic function so it is given as

$F_{i}\left(P_{i}\right)=a_{i} P_{g i}^{2}+b_{i} P_{g i}+c_{i}$ 
Subjected to

$$
\begin{aligned}
& \sum_{i=1}^{n} P_{i}=P_{D}+P_{L} \\
& P_{i, \text { min }} \leq P_{i} \leq P_{i, \max }
\end{aligned}
$$

Where $a_{i}, b_{i}, c_{i}$ are fuel cost coefficients of the $i^{\text {th }}$ thermal generating unit,

$P_{i}=$ The real power of generating unit $\mathrm{i}$,

$P_{D}=$ Total load demand,

$P_{L}=$ Total transmission line loss,

$P_{i, \min }=$ The minimum generation limit of unit $\mathrm{i}$ and

$P_{i, \max }=$ The maximum generation limit of unit $\mathrm{i}$.

\section{Economic Dispatch Problem with Valve-Point Loading} Effect

Sinusoidal functions are added with the quadratic function of fuel cost to represent the valve-point loading effects. It follows as [11-14]

$$
F_{i}\left(P_{i}\right)=a_{i}+b_{i} P_{i}+c_{i} P_{i}^{2}+\left|e_{i}^{*} \sin \left(f_{i}^{*}\left(P_{i}^{\min }-P_{i}\right)\right)\right|
$$

Where $e_{i}$ and $f_{i}$ are coefficient of the generating units reflecting valve-point loading effects.

The transmission line losses are written as

$$
P_{L}=\sum_{i=1}^{n} \sum_{j=1}^{n} P_{i} B_{i j} P_{j}+\sum_{i=1}^{n} P_{i} B_{0 i}+B_{00}
$$

Where $\mathrm{B}_{\mathrm{ij}}, \mathrm{B}_{0 \mathrm{i}}$ and $\mathrm{B}_{00}$ are transmission line loss coefficients,

\section{T \& L BASEd OPTIMIZATION Algorithm}

Teaching and Learning (T\&L) inspired optimization process proposed by Rao and Savsani [16-17] and Rao and Patel [18] depends on Teacher and Learner Mechanism. The Teaching and Learning (T\&L) based optimization is a metaheuristic population based search algorithm like HSA, Ant Colony Optimization (ACO), PSO and Artificial Bee Colony (ABC). The Teaching and Learning (T\&L) based optimization method is a simple mathematical model to solve different optimization problems.

In this work concentrates on a new optimization algorithm that is Teaching and Learning (T\&L) based optimization. Incorporated $\mathrm{T} \& \mathrm{~L}$ based optimization algorithm is effective remedy for diminishing the flaws in traditional approach like provincial optimal trapping, inadequate effective to identify nearby extreme points and inefficient mechanism to analyzing the constraints.
According to our T\&L based optimization algorithm a learner can gains knowledge in two ways: (i) by teacher (called teacher phase) and (ii) interacting with the neighbor learners (called learner phase). In this algorithm learners are called as population. Design variable are called as subjects of the learners. The best learner is treated as Teacher.

\section{Teacher Phase:}

Pupil gains knowledge from the instructor ever and instructor should improve the mean result of class by his skills. The best learner is that once knowledge is equal to the teachers knowledge means teacher make to learners to reach his knowledge. But practically is not possible because all learners are not cleverers. This follows as [19].

Let $M_{i}=$ Mean

$T_{i}=$ Teacher at any iteration i.

$T_{i}$ Makes the mean $M_{i}$ to move towards its own knowledge level, therefore $T_{i}$ chosen as $\mathrm{M}_{\text {new }}$. Hence the best learner is treated as teacher. The difference of the current mean result of every subject and the corresponding result of the teacher for every subject is given by,

$$
\text { Difference }=r *\left(M_{\text {new }}-T_{F} M_{i}\right)
$$

Where $T_{F}=$ Teaching factor. It is given as follows:

$$
T_{F}=\operatorname{round}[1+\operatorname{rand} *(0,1) *(2-1)]
$$

This difference modifies the existing solution according to the following expression

$$
X_{n e w, i}=X_{o l d, i}+\text { difference }
$$

Where $X_{n e w, i}$ is the updated value of $X_{\text {old }, i}$. Accept $X_{\text {new }, i}$

\section{Learner phase:}

The input for the learner phase is the teacher in learner phase learner gains knowledge learner gains knowledge by two ways: one is gaining knowledge form teacher and other is by sharing knowledge between learners interaction.

The learner phase is shows as follows.

Randomly select two learners and where $\mathrm{i} \neq \mathrm{j}$

$$
\begin{aligned}
& X_{\text {new }, i}=X_{\text {old }, i}+r *\left(X_{i}-X_{j}\right) \text { if } f\left(X_{i}\right)<f\left(X_{j}\right) \\
& X_{\text {new }, i}=X_{\text {old }, i}+r *\left(X_{j}-X_{i}\right) \text { if } f\left(X_{i}\right)>f\left(X_{j}\right)
\end{aligned}
$$

Admit $X_{\text {new }, i}$ if it gives better function value

\section{Comparison of T\&L Based Optimization Algorithm With Other Algorithms}

There are several algorithms like GA, PSO, ABC, HSA, etc. The proposed the effectiveness of T\&L based Optimization on 6 unit test system and compared with PSO, DE, HSA. 
Finally $\mathrm{T} \& \mathrm{~L}$ based optimization technique gives the high quality solution.

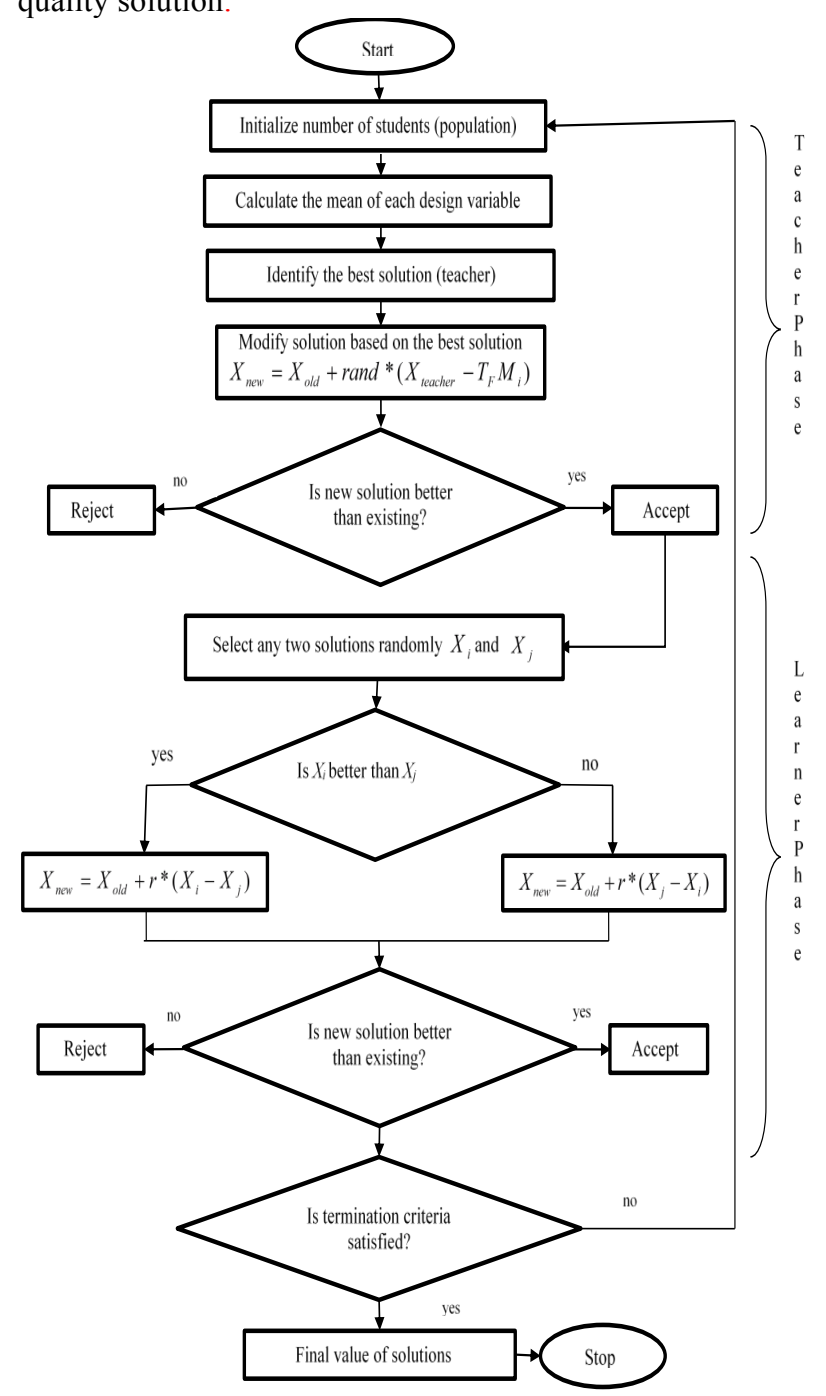

Fig.1 Flow Chart of T \& L based optimization algorithm

Table 1. Global generations for 6unit system

\begin{tabular}{|c|c|c|c|c|}
\hline \multirow{2}{*}{$\begin{array}{c}\text { Number of } \\
\text { units }\end{array}$} & \multicolumn{4}{|c|}{ Global generations in MW } \\
\cline { 2 - 5 } & PSO & HSA & DE & TLBO \\
\hline 1 & 400.6115 & 399.4068 & 500 & 500 \\
\hline 2 & 199.5996 & 200 & 149.9957 & 151.4009 \\
\hline 3 & 232.1225 & 232.0630 & 230.3581 & 300 \\
\hline 4 & 124.7998 & 125.2627 & 125.8899 & 87.7215 \\
\hline 5 & 199.5996 & 200 & 149.9629 & 149.4573 \\
\hline 6 & 120 & 120 & 120 & 88.4572 \\
\hline $\begin{array}{l}\text { Min.cost } \\
\text { (\$h) }\end{array}$ & 15616.7991 & 15624.4473 & 15615.6937 & 15611.6988 \\
\hline $\begin{array}{l}\text { Power loss } \\
\text { (MW) }\end{array}$ & 13.7331 & 13.5483 & 13.2068 & 14.0371 \\
\hline
\end{tabular}

\section{Simulation Results and Discussion}

The Proposed T \& L based Optimization algorithm was implemented for two cases case: 1 consisting 6-Baseload generation units preferring loading valve point loading effect and losses. The T \& L based optimization algorithm was written using MATLAB 7.9.0(R2009a) running on i5 processor, $2.56 \mathrm{GHz}, 8 \mathrm{~GB}$ RAM, PC.

\section{Case 1}

This case contains 6-base load generation units considering loading valve point loading effect and losses. The generating units have to meet the load demand of 1263MW. To calculate the efficiency of the $\mathrm{T} \& \mathrm{~L}$ based optimization method, 25 individual trails can made at 60 -population with 200 iterations per trail.

The comparisons of cost and global are tabulated in Table 1 and Table 2. The global generations and the independent trails convergence characteristics are also plotted which are shown in fig. 2 and 3 respectively.

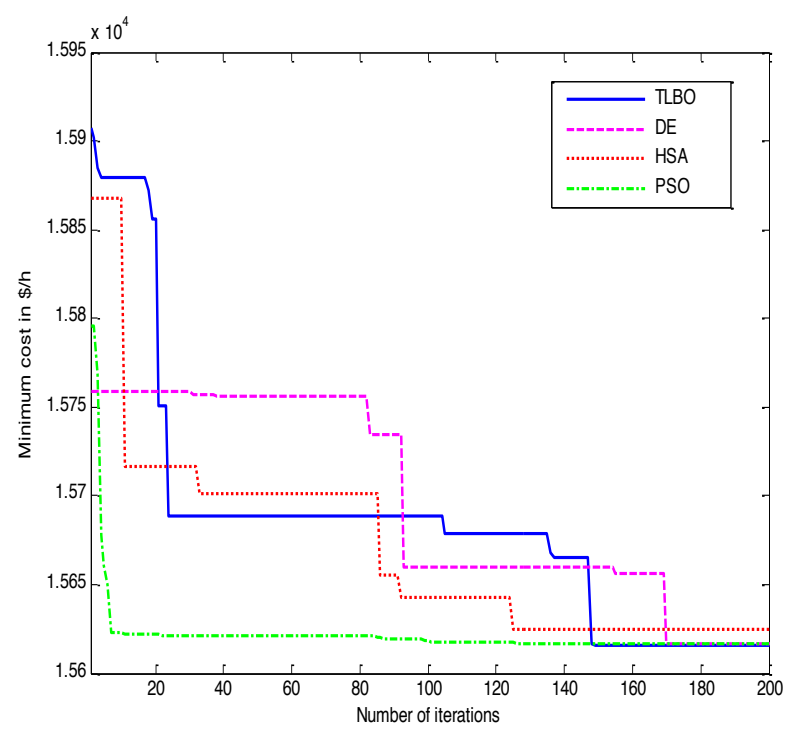

Fig. 2 Convergence characteristics of 6 unit system

Table 1 clearly shows that for PSO the minimum cost attained was $15616.7991 \$ / \mathrm{h}$, for HSA the minimum cost attained was $15624.4473 \$ / \mathrm{h}$, for $\mathrm{DE}$ the minimum cost attained was $15615.6937 \$ / \mathrm{h}$, and for TLBO the minimum cost attained was 15611.6988. Hence the above results shows that, the minimum cost is attained for TLBO as compared with the other algorithms. The power loss attained for TLBO was 14.0371MW.

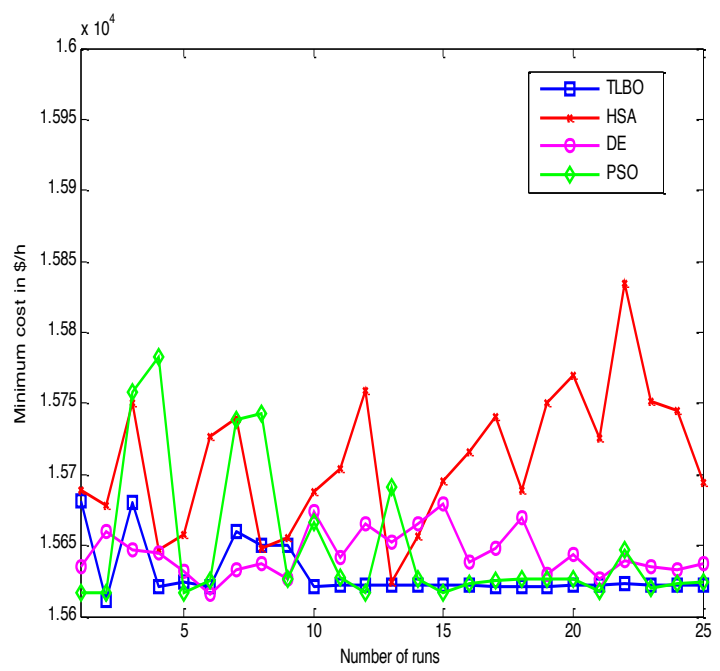

Fig. 3 Comparison characteristics of minimum costObtainedfor 25 runs

Case 2

This case consists of ten thermal generation units considering loading valve point loading effect and losses. The generating units have to meet the load demand of 2000 MW. To calculate the efficiency of the T \& L based 
optimization method, 25 individual trails can made at 100 population with 200 iterations per trail.

Table 2. Minimum cost obtained for 25 runs

\begin{tabular}{|c|c|c|c|c|}
\hline \multirow{2}{*}{$\begin{array}{c}\text { Number } \\
\text { of runs }\end{array}$} & \multicolumn{4}{|c|}{ Minimum cost in $\$ / h$} \\
\hline & PSO & HSA & DE & TLBO \\
\hline 1 & 15616.8546 & 15688.4303 & 15635.2652 & 15681.9111 \\
\hline 2 & 15616.8756 & 15677.7093 & 15660.2286 & 15611.6988 \\
\hline 3 & 15758.1765 & 15750.0689 & 15646.7544 & 15680.6254 \\
\hline 4 & 15782.4748 & 15647.0857 & 15645.1185 & 15621.5284 \\
\hline 5 & 15616.8511 & 15657.9900 & 15631.8830 & 15624.2276 \\
\hline 6 & 15625.1855 & 15726.5923 & 15615.6937 & 15621.4526 \\
\hline 7 & 15738.7735 & 15739.6564 & 15632.6176 & 15659.3512 \\
\hline 8 & 15743.2094 & 15647.9531 & 15636.6707 & 15650.3453 \\
\hline 9 & 15626.6348 & 15655.4437 & 15626.5942 & 15650.3141 \\
\hline 10 & 15665.8478 & 15688.3176 & 15673.4684 & 15621.5109 \\
\hline 11 & 15627.0714 & 15703.6266 & 15641.7270 & 15622.5178 \\
\hline 12 & 15616.7991 & 15759.3145 & 15665.2332 & 15621.6119 \\
\hline 13 & 15691.2273 & 15624.4473 & 15652.6820 & 15622.4532 \\
\hline 14 & 15626.6205 & 15656.2226 & 15665.7099 & 15622.1312 \\
\hline 15 & 15616.9367 & 15695.9180 & 15679.2265 & 15621.6684 \\
\hline 16 & 15623.5040 & 15715.6528 & 15638.6161 & 15621.6008 \\
\hline 17 & 15625.1855 & 15740.7103 & 15648.2682 & 15621.5467 \\
\hline 18 & 15626.5741 & 15688.7322 & 15670.0528 & 15621.3824 \\
\hline 19 & 15626.7418 & 15750.1998 & 15629.4167 & 15620.9401 \\
\hline 20 & 15626.7085 & 15769.2848 & 15643.9360 & 15621.6385 \\
\hline 21 & 15618.0267 & 15725.9458 & 15626.4920 & 15622.2550 \\
\hline 22 & 15647.0017 & 15834.2254 & 15639.1709 & 15622.9964 \\
\hline 23 & 15619.6076 & 15751.9471 & 15635.1169 & 15621.7541 \\
\hline 24 & 15623.5005 & 15744.5482 & 15633.0052 & 15622.5070 \\
\hline 25 & 15624.3020 & 15694.8515 & 15637.5919 & 15621.6983 \\
\hline $\begin{array}{l}\text { Min. } \\
\text { cost } \\
(\$ / \mathbf{h})\end{array}$ & 15616.7991 & 15624.4473 & 15615.6937 & 15611.6988 \\
\hline $\begin{array}{l}\text { Max. } \\
\text { cost } \\
(\mathbb{\$} / \mathbf{h})\end{array}$ & 15782.4748 & 15834.2254 & 15679.2265 & 15681.9111 \\
\hline $\begin{array}{l}\text { Avg. } \\
\text { cost } \\
(\$ / h)\end{array}$ & 15649.2276 & 15709.3950 & 15644.4216 & 15630.0667 \\
\hline
\end{tabular}

The comparisons of cost and global are tabulated in Table 3 and Table 4. The global generations and the independent trails convergence characteristics are also plotted which are shown in fig 4 and 5 respectively.

Table 3. Global generations for 10unit system

\begin{tabular}{c|c|c|c|c}
\hline \multirow{2}{*}{$\begin{array}{c}\text { Number } \\
\text { of units }\end{array}$} & \multicolumn{4}{|c}{ Global generation in $\boldsymbol{M W}$} \\
\cline { 2 - 5 } & PSO & HSA & DE & TLBO \\
\hline 1 & 55 & 50.8495 & 55 & 55 \\
2 & 80 & 75.8420 & 78.7733 & 80 \\
3 & 107.3388 & 115.8420 & 99.3983 & 106.9392 \\
4 & 100.3117 & 94.02348 & 107.1068 & 100.5765 \\
5 & 81.4700 & 109.7019 & 89.0972 & 81.5012 \\
6 & 82.9208 & 95.2030 & 81.4078 & 83.0217 \\
7 & 300 & 295.8420 & 296.1400 & 300 \\
8 & 340 & 335.8420 & 340 & 340 \\
9 & 470 & 465.8420 & 470 & 470 \\
10 & 470 & 446.8475 & 470 & 470 \\
\hline $\begin{array}{c}\text { Min.cost } \\
\text { (\$/h) }\end{array}$ & 111497.6596 & 111907.4666 & 111537.6219 & 111497.6301 \\
\hline $\begin{array}{c}\text { Power } \\
\text { loss }\end{array}$ & 87.0414 & 85.8360 & 86.9237 & 87.0387 \\
(MW) & & & & \\
\hline
\end{tabular}

Table 3 shows that for PSO the minimum cost attained was $111497.6596 \$ / \mathrm{h}$, for HSA the minimum cost attained was $111907.4666 \$ / \mathrm{h}$, for $\mathrm{DE}$ the minimum cost attained was $111537.6219 \$ / \mathrm{h}$, and for TLBO the minimum cost attained was 111497.630 . Hence the above results shows that, the minimum cost is attained for TLBO as compared with the other algorithms. The power loss attained for TLBO was 87.0387MW
Table 4. Minimum cost obtained for 25 runs

\begin{tabular}{|c|c|c|c|c|}
\hline \multirow{2}{*}{$\begin{array}{l}\text { Number of } \\
\quad \text { runs }\end{array}$} & \multicolumn{4}{|c|}{ Minimum cost in $\$ / h$} \\
\hline & PSO & HSA & $\overline{D E}$ & TLBO \\
\hline 1 & 111641.4441 & 111959.2697 & 111569.1983 & 111500.9854 \\
\hline 2 & 111525.8322 & 112694.2246 & 111673.5325 & 111505.7236 \\
\hline 3 & 111497.6763 & 111947.6861 & 111695.2852 & 111497.6765 \\
\hline 4 & 111521.5108 & 112047.7053 & 111567.3306 & 111521.7364 \\
\hline 5 & 111525.8275 & 112302.8949 & 111742.5223 & 111525.7565 \\
\hline 6 & 111525.6877 & 112206.2944 & 111743.0718 & 111521.5768 \\
\hline 7 & 111525.7571 & 112052.4801 & 111670.3818 & 111502.6754 \\
\hline 8 & 111525.7976 & 112071.9085 & 111705.6591 & 111505.8768 \\
\hline 9 & 111525.8834 & 111947.8623 & 111751.1809 & 111497.6301 \\
\hline 10 & 111497.7631 & 111987.3196 & 111648.195 & 111497.6764 \\
\hline 11 & 111497.6695 & 111919.8793 & 111645.2498 & 111497.6765 \\
\hline 12 & 111497.7148 & 112337.6419 & 111601.2568 & 111497.6987 \\
\hline 13 & 111497.6784 & 112250.1165 & 111689.5033 & 111497.6877 \\
\hline 14 & 111525.7557 & 112185.1190 & 111663.6215 & 111500.6301 \\
\hline 15 & 111497.8285 & 112235.6711 & 111679.4047 & 111504.6375 \\
\hline 16 & 111497.7403 & 112094.2826 & 111654.574 & 111525.6384 \\
\hline 17 & 111525.6996 & 112026.1773 & 111629.5029 & 111518.6311 \\
\hline 18 & 111525.7043 & 112125.7557 & 111537.6219 & 111499.6343 \\
\hline 19 & 111525.5897 & 112010.5037 & 111706.3123 & 111497.6301 \\
\hline 20 & 111525.8344 & 112131.3220 & 111714.4087 & 111497.6301 \\
\hline 21 & 111525.7345 & 112421.2877 & 111551.2658 & 111497.6301 \\
\hline 22 & 111525.7724 & 112461.9869 & 111675.4585 & 111499.6383 \\
\hline 23 & 111497.6596 & 112385.1277 & 111707.5187 & 111499.6376 \\
\hline 24 & 111525.71 & 112111.6850 & 111608.6125 & 111497.6301 \\
\hline 25 & 111497.7123 & 111907.4666 & 111652.1783 & 111497.6301 \\
\hline $\begin{array}{c}\text { Min } \\
\operatorname{cost}(\$ / h)\end{array}$ & 111497.6596 & 111907.4666 & 111537.6219 & 111497.6301 \\
\hline $\begin{array}{c}\text { Max. } \\
\operatorname{cost}(\$ / h)\end{array}$ & 111641.4441 & 112694.2246 & 111751.1809 & 111525.7565 \\
\hline $\operatorname{Avg} \cdot \cos t(\$ / h)$ & 111520.1193 & 112152.8667 & 111659.3138 & 111504.2789 \\
\hline
\end{tabular}

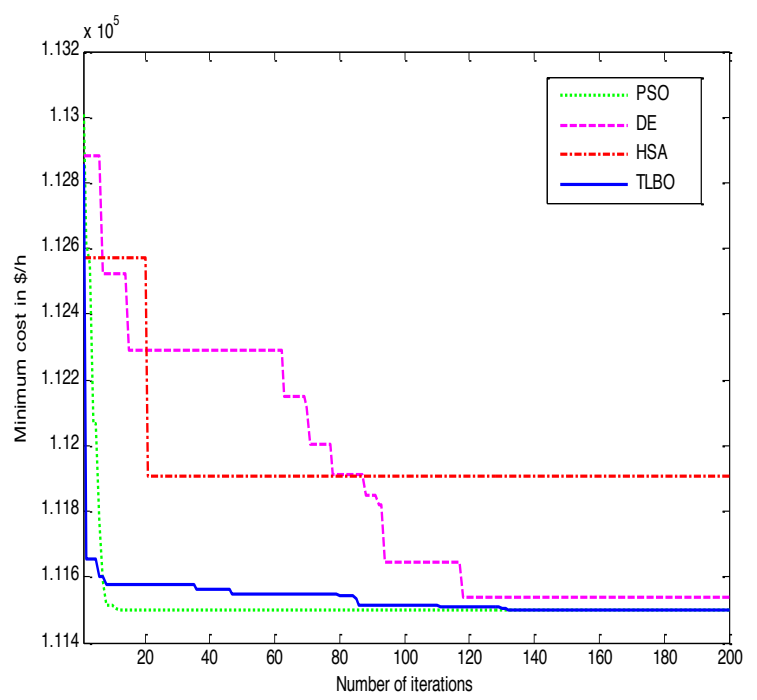

Fig.4 Convergence characteristics of 10-unit system 


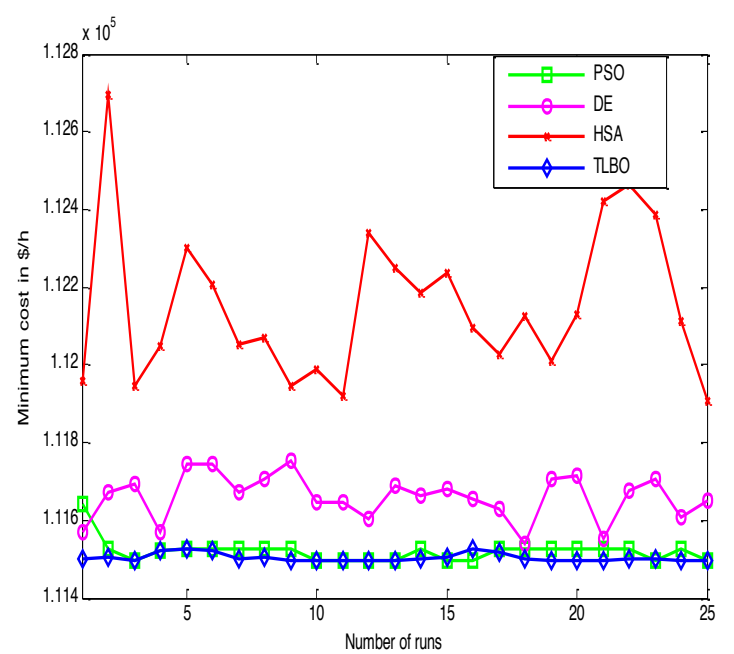

Fig. 5 Comparison characteristics of minimum cost obtained for 25 runs

\section{Conclusion}

Hence form the above results we can conclude that Incorporated $\mathrm{T} \& \mathrm{~L}$ based optimization algorithm is Effective remedy for diminishing the flaws in traditional approach like provincial optimal trapping, inadequate effective to identify nearby extreme points and inefficient mechanism to analyzing the constraints. The proposed T\&L based optimization on 6 unit test system, 10 unit test system compared with PSO, DE, HSA. Finally TL based optimization technique gives the Effective high quality solution for Economic load dispatch problem.

This is an Open Access article distributed under the terms of the Creative Commons Attribution Licence

\section{References}

1. Allen J. Wood, Bruce F. Wollenberg, "Power Generation, Operation, and Control", Second Edition, A Wiley Interscience Publication, New York 1996.

2. Nima Amjady, Hadi Nasiri Rad, "Solution of nonconvex and nonsmooth economic dispatch by a new Adaptive Real Coded Genetic Algorithm", Expert Systems with Applications, vol. 37, pp. 5239-5245, 2010.

3. Worawat Sa-ngiamvibool, Saravuth Pothiya, Issarachai Ngamroo, "Multiple tabu search algorithm for economic dispatch problem considering valve-point effects", Electrical Power and Energy Systems, vol. 33, pp. 846-854, May 2011.

4. David C. Walters, Gerald B. Sheble, "Genetic Algorithm Solution Of Economic Dispatch With Valve Point Loading", IEEE Transactions on Power Systems, Vol. 8, No. 3, PP. 1325-1332, August 1993.

5. Amita Mahor a, Vishnu Prasad, Saroj Rangnekar, "Economic dispatch using particle swarm optimization: A review", Renewable and Sustainable Energy Reviews, vol. 13, pp. 2134 2141, 2009.

6. X. Xia, A.M. Elaiw, "Optimal dynamic economic dispatch of generation: A review”, Electric Power Systems Research, vol. 80, pp. 975-986, 2010.

7. Chakraborty S, Senjyu T, Yona A, Saber AY, Funabashi T, "Solving economic load dispatch problem with valve-point effects using a hybrid quantum mechanics inspired particle swarm optimization", IET Generation Transmission and Distribution, vol. 5, no. 10, pp. 1042-1052, 2011.

8. Nima Amjady, Hossein Sharifzadeh, "Solution of non-convex economic dispatch problem considering valve loading effect by a new modified differential evolution algorithm", Electrical Power and Energy Systems, vol. 32, pp. 893-903, 2010.

9. Ling Wang, Ling-po Li, “An effective differential harmony search algorithm for the solving non-convex economic load dispatch problems", Electrical Power and Energy Systems, vol. 44, pp. 832-843, 2013.

10. A. Immanuel Selvakumar and K. Thanushkodi, "A new particle swarm optimization solution to nonconvex economic dispatch problem," IEEE Trans. Power Systems, vol. 22, no. 1, pp. 42-51, 2007.

11. N. Noman and H. Iba, "Differential evolution for economic load dispatch problems.” Electric Power System Research, vol. 78, pp. 1322-31, 2008.

12. Nima Amjady, Hossein Sharifzadeh, "Solution of non-convex economic dispatch problem considering valve loading effect by a new modified differential evolution algorithm", Electrical Power and Energy Systems, vol. 32, pp. 893-903, 2010.

13. Ling Wang, Ling-po Li, "An effective differential harmony search algorithm for the solving non-convex economic load dispatch problems", Electrical Power and Energy Systems, vol. 44, pp. 832-843, 2013.

14. Leandro dos Santos Coelho, Viviana Cocco Mariani, "An improved harmony search algorithm for power economic load dispatch", Energy Conversion and Management, vol. 50, pp. 2522-2526, 2009.

15. Dexuan Zou, Steven Li, Gai-Ge Wang, Zongyan Li, Haibin Ouyang, "An improved differential evolution algorithm for the economic load dispatch problems with or without valve-point effects", Applied Energy, vol. 181, pp. 375-390, 2016.

16. R.V. Rao, V.J. Savsani, D.P. Vakharia, "Teaching-learning-based optimization: A novel method for constrained mechanical design optimization problems", Computer-Aided Design, vol. 43, pp.303-315, 2011.

17. R.V. Rao, V.J. Savsani, D.P. Vakharia, "Teaching-Learning-Based Optimization: An optimization method for continuous non-linear large scale problems", Information Sciences, vol. 183, pp. 1-15, 2012.

18. R.VenkataRao,Vivek Patel, "An improved teaching-learning-based optimization algorithm for solving unconstrained optimization problems", Scientia Iranica D, vol. 20, pp. 710-720, 2013.

19. Sumit Banerjee, Deblina Maity, Chandan Kumar Chanda, "Teaching learning based optimization for economic load dispatch problem considering valve point loading effect",Electrical Power and Energy Systems, vol. 73, pp. 456-464, 2015.

20. Irina Ciornei and Elias Kyriakides, "A GA-API Solution for the Economic Dispatch of Generation in Power System Operation", IEEE Transactions on power systems, vol. 27, no. 1, pp. 233-242, 2012. 